\title{
Investigating the factors driving adult learners' continuous intention to use M-learning application: a fuzzy-set analysis
}

\author{
Md Nahin Hossain \\ Center for Modern Information Management, School of Management, \\ Huazhong University of Science and Technology, Wuhan, China \\ Md. Shamim Talukder \\ Department of Management, School of Business and Economics, \\ North South University, Dhaka, Bangladesh, and \\ Abul Khayer and Yukun Bao \\ Center for Modern Information Management, School of Management, \\ Huazhong University of Science and Technology, Wuhan, China
}

\begin{abstract}
Purpose - In the era of m-learning environments, multiple factors have been considered to explain adult learners' continuance usage intention, but largely without considering the role of specific configurations of variables and how they may affect learners' intention. The purpose of this study is to show how cognitive need, subjective norms, perceived usefulness, satisfaction, confirmation, attitude and perceived ease of use combine to predict learners' frequent use intentions.

Design/methodology/approach - It is empirically validated through configurational analysis, using fuzzyset qualitative comparative analysis (fsQCA) on 211 adult learners with experience in using Mobile learning applications (MLA).

Findings - The findings show learners' satisfaction of MLA usage combined with the cognitive need and attitude were found to be core conditions reinforcing learners' continuance intention.

Research limitations/implications - This study was conducted in the context of adult learners MLA whereby the motivations for continued usage and the nature of technological innovation could differ. In this regard, findings from this study may not be generalizable to other technological contexts.

Practical implications - In the planning and development of learning apps, software developers should pay attention to practical functions and extend key features that are frequently required for solving a problem using the new skill. On the marketing side, MLA companies should emphasize the full functionality of their apps to cater efficiently to the different needs and expectations of the learners.

Originality/value - This study contributes by extending existing knowledge on how cognitive need, satisfaction and attitude combine to increase or mitigate continuance intention to use toward the development of new configurational theories. This study fills the gap in the literature by introducing adult learners' continuance intention to use MLA and introducing through a methodological approach of fsQCA in adult learners' context.
\end{abstract}

Keywords M-learning application (MLA), Cognitive need, Adult learners, Continuance intention, Fuzzy-set qualitative comparative analysis ( $\mathrm{f} \mathrm{QCA}$ )

Paper type Research paper

(C) Md Nahin Hossain, Md. Shamim Talukder, Abul Khayer and Yukun Bao. Published in Journal of Research in Innovative Teaching \& Learning. Published by Emerald Publishing Limited. This article is published under the Creative Commons Attribution (CC BY 4.0) licence. Anyone may reproduce, distribute, translate and create derivative works of this article (for both commercial and non-commercial purposes), subject to full attribution to the original publication and authors. The full terms of this licence may be seen athttp://creativecommons.org/licences/by/4.0/legalcode
Analysing adult learners in using M-learning

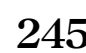

Received 27 September 2019 Revised 16 January 2020 Accepted 6 March 2020

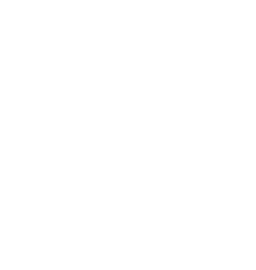




\section{Introduction}

The advent of Mobile learning applications (MLA) has created innovative beginnings for the educator to develop an education system for adult learners using digital media (Alario Hoyos et al., 2014). Instructors now access expertise that let informal learners inhabit in collaborative and supportive learning despite in different time and place (Alario-Hoyos et al., 2013). Most of the elite institutions have launched MLA such as Xueda, uDA and OCS3 to promote academic development on this platform. Even with public enthusiasm for this platform, it has been suffering from enormous dropout rates. On average, not more than $10 \%$ of learners enrolling the learning app complete their course (Bartolomé-Pina and Steffens, 2015). Considering the dropout rates, a subject of countless discomfort has been focused on the issues of quality in learning and teaching (Diver and Martinez, 2015). However, except for the completion rate, there are other determinants for assessing learning using mobile apps (Jordan, 2015) because students choose to register in the courses for a variety of reasons. For example, a student who completes course tend to be more concerned in the course content, and others tend to be more attracted in the new type of learning experience (Chiang et al., 2014). Bhattacherjee (2001) posited that the continued usage of an Information System (IS) is vital to its market success because the benefits to be gained from any IS investment can only be realized then the system is subjected to continuous use by its target audience. Consequently, deciphering the motivations driving the continued usage of learning app has attracted substantive attention among researchers within the IS field. Therefore, the success of MLA is based on its continuance usage.

Previous studies on the continuous use of MLA engage numerous statistical techniques, such as multiple regression analysis (MRA) and structural equation modeling (SEM), for analysis. Such practices generally assume symmetrical relationships between predictors (e.g. motivators) and outcomes (e.g. continued usage of MLA). That is why every predictor is projected to exert a significant impact on the outcome of interest. Despite the popular regression analysis and other statistical techniques, they hardly adequate in describing complex relational interaction and their effects among multiple predictors that could influence the continued usage of social media by users (Liu et al., 2017; Park and El Sawy, 2012; Ragin, 2000; Woodside, 2013). As alleged by Liu et al. (2017), numerous sufficient situations could mutually forecast whether learners are likely to continue using an IS and that these conditions cannot demonstrate by regular regression-based methods (Kibelloh and Bao, 2014).

A primary contention of Liu et al. (2017) is that interactions between predictors and learning app usage behaviors could also be asymmetric, which in turn lends credibility to configurational techniques, such as fuzzy-set qualitative comparative analysis (fsQCA), as an alternative approach for exploring learning app usage behavior. Configuration theories describe that the combinations of discrete conditions can lead to the same outcome. The mutual relationships between predictors and outcomes seem to be more asymmetric rather than symmetric (Liu et al., 2017; Park and El Sawy, 2012; Ragin, 2000; Woodside, 2013). Venkatesh et al. (2003) argued that users' decision to use an MLA regularly derives from the perceptions of system qualities, which originated from past practice experience. Learners, after primary usage, may agree not to continue using an app if only a few conditions met. In other words, a single condition (no matter how crucial) may not be sufficient enough for users' intention to continue using the digital application for learning. Therefore, it is apparent that regular regression methods are inconsistent with asymmetrical relationships.

This study tries to improve an in-depth appreciation of the configuration of conditions by using fsQCA that culminate in learners' continuance intention toward MLA. Moreover, this study contributes to the technology continuance theory (TCT) as our theoretical lens for deriving essential proportions. Precisely, fsQCA is engaged to inspect the asymmetric 
relationships of the theoretical component of 'TCT and users' continuance intention toward MLA, which become a popular way of learning among professional learners in Bangladesh.

The contribution of this paper in the literature is twofold. First, we cover the previous works by exploring how adult learners choose MLA, through the lens of perceived usefulness, confirmation, perceived ease of use, satisfaction and attitude. This study inspects their combined effects on intention to use MLA continuously. Second, we use fsQCA for data analysis which is an advanced methodology. It offers a deeper insight into the data and generally considered as a complementary method of regular variance-based approaches. Recognizing the relationship among the said constructs should facilitate educators and practitioners to understand comprehensive outlines of the issues that motivate adult learners' continuous intentions and help them create better-targeted learning apps with improved content quality and value.

This paper is organized as follows. In the second section, the theoretical background on antecedents of continuous intention to use MLA (M-learning application) is presented, along with a discussion on the conceptual model. The third section describes the research methodology and provides details on fsQCA and how it is implemented. The fourth section presents the empirical results from the configurational analysis with fsQCA. Finally, the fifth section discusses the findings highlighting theoretical, methodological and practical implications, along with limitations and avenues for future research.

\section{Literature review}

\section{Adult learners and M-learning application (MLA)}

Adult learners in South Asian countries like Bangladesh who are potentially involved in the creation of the knowledge-based economy and decision-making are adults who are contributing actively to the economy of Bangladesh (Farooqui, 2007; Jamila, 2014). This group of adults, according to the literature, is defined on the bases of their sociocultural roles, status and responsibilities (Alkin, 1992; Jarvis, 1990; Tight, 2000; Tuijnman, 1996). Knowles (1998) stated that "we become adult psychologically when we arrive at a self-concept of being responsible for our own lives, of being self-directing" and "we become adult socially when we start performing adult roles, such as the role of full-time worker, spouse, parent, voting citizen, and the like" (p. 64). Hence, the "functions" and "roles" of these adults, (not their "biological age"), determine the definition of adulthood in the context of the knowledge-based economy in the current study. This definition of adult learners is also endorsing in the recent statistics on the most active participation age group in adult education. The age group between 30 and 54 years was found to be the most active adult participants in both Finland (see Blomqvist et al., 1995) and the United States of America (see Caffarella and Merriam, 2000). Hence, it is highly possible that a similar age range of Bangladeshi adults (i.e. age between 30 and 54 years), who have professional work experience, also belong to the group who are actively seeking continuing professional education or other forms of formal education to enhance knowledge and learning in view of the changing scene in the global market.

Thus, adult learners can be characterized as self-directed, highly motivated and know what they want to achieve from their education program (Huang, 2002). These students are motivated by career development, job security, upward mobility, recareering and other professional and personal reasons (Katz, 1999; Eastmond, 1998). Their life experience usually aids adult learners, and their reflections and actions are integral components of the adult learning process (Merriam and Caffarella, 1991). According to Ruey (2010), for the MLA process to be successful, adult learners should be able to interact with the course materials, discuss and collaborate between instructor and other students, and integrate their past experience with the course content or assignment. Adult learners enjoy having discussions 
JRIT

14,2

and relating course materials to their lives, use their experiences as a learning resource, are problem-centered and prefer "immediacy of application" (Morris, 2010). In other words, to actively engage adult learners in MLA, the program should be able to encourage them to discuss, argue, negotiate ideas and collaboratively solve problems (Ruey, 2010). This approach is said to be appropriate for adult learners because their learning context usually requires them to integrate their rich life and employment experiences in learning. Thus, to make a success, the MLA used should be able to support these needs. MLA that offer these needs is said to have a better likelihood to be used and adopted by adult learners (Eastmond, 1998; Huang, 2002).

\section{Definition of construct}

\begin{tabular}{|c|c|}
\hline Construct & Definition \\
\hline Subjective norms & $\begin{array}{l}\text { Subjective norm is the perceived social pressure to engage or not to engage in a behavior } \\
\text { (Ahn and Kahlor, 2019; Pender and Pender, 1986; Tarkiainen, 2005) }\end{array}$ \\
\hline Cognitive need & $\begin{array}{l}\text { Cognitive needs refer to the desire to know, understand and solve problems. People with } \\
\text { strong cognitive needs are often described as curious and inquisitive (Aliberti et al., } \\
\text { 2019; Loetscher } \text { et al., 2019) }\end{array}$ \\
\hline Confirmation & $\begin{array}{l}\text { Confirmation refers to the judgments or evaluations that a person makes with respect to } \\
\text { a product, service or technology artifact. These evaluations or judgments are made in } \\
\text { comparison to the person's original expectations (Huang, 2019; Leung and Chen, 2019) }\end{array}$ \\
\hline Satisfaction & $\begin{array}{l}\text { Satisfaction refers to the extent to which a person is pleased or contented with a product, } \\
\text { service or technology artifact after having gained direct experience with the product, } \\
\text { service or artifact (San Martín et al., 2019; Willroth et al., 2019) }\end{array}$ \\
\hline Attitude & $\begin{array}{l}\text { Attitude is defined as a response to technology adaption in life. It can be referred to as a } \\
\text { person's viewpoint, mindset, beliefs about the services (Giles, 2019; Wang et al., 2019) }\end{array}$ \\
\hline $\begin{array}{l}\text { Perceived ease of } \\
\text { use }\end{array}$ & $\begin{array}{l}\text { The degree to which a person believes that using a particular system would be free from } \\
\text { effort. If the technology is easy to use, then the barriers conquered. If it is not easy to use } \\
\text { and the interface is complicated, no one has a positive attitude toward it (Roberts et al., } \\
\text { 2019; Rakoczy et al., 2019) }\end{array}$ \\
\hline $\begin{array}{l}\text { Perceived } \\
\text { usefulness }\end{array}$ & $\begin{array}{l}\text { The degree to which a person believes that using a particular system would enhance his } \\
\text { or her performance. It means whether or not someone perceives that technology to be } \\
\text { useful for what they want to do (Chang and Chen, 2019) }\end{array}$ \\
\hline $\begin{array}{l}\text { Continuous } \\
\text { intention }\end{array}$ & Persistent behavior of a user to use the service repeatedly (Hsu and Lin, 2019) \\
\hline
\end{tabular}

\section{Theoretical foundation}

Antecedents of continuance intention to use M-learning apps (MLA)

With the rapid growth of e-learning, particularly in higher education institutions (Demirkan et al., 2010; Loh et al., 2015; Weng et al., 2015), successful e-learning has been discussed and investigated in various studies, from different perspectives and in different contexts (Alias et al., 2012; Bhuasiri et al., 2012; Govindasamy, 2001; Holsapple and Lee-Post, 2006; Lieblein, 2000; Sela et al., 2009; Selim, 2007; Song et al., 2003; Swan et al., 2000; Volery and Lord, 2000). Bhattacherjee (2001) proposed a postacceptance model of information system usage continuance by adapting expectation-confirmation theory. This theoretical model reflects users' perceptions of the usefulness of and satisfaction with a system as related to their continuance intention. Demirkan et al. (2010) discussed a reference model for sustainable m-learning systems. Ho (2010) proposed an integrated technology acceptance model (TAM), an expectation-confirmation model (ECM), a cognitive model and a self-determination model, and examined how motivational factors affect the synthesized model. Ho (2010) demonstrated 
that perceived usefulness, user satisfaction and attitudes could significantly predict users' e-learning continuance intention. Lin et al. (2011) developed a model that examined users' e-learning continuance intention concerning negative critical incidents. They found that negative critical incidents, perceived ease of use, perceived usefulness, satisfaction and attitudes were the core factors related to users' MLA continuance intentions (Thongsri et al., 2019). Lee $e$ al. (2011) noted that the intention to continue using learning apps remains very low, particularly after initial acceptance of the system, and that satisfaction was found to be the strongest predictor for driving users' continuance intention. Based on Ifinedo (2006), this may be due to certain technological characteristics that influence students' perceived behavior and hence affect their usage and continuation intention with regard to e-learning systems. In addition, Liao et al. (2009) integrated TAM, ECM and the cognitive model in order to explain what drives users to continue with information system use. They proposed the constructs of confirmation, perceived usefulness, perceived ease of use, satisfaction, attitude and continuance intention to shape their TCT.

\section{Technology continuance theory}

The TCT has been used to describe the continuance usage intent of the MTB app among users in this study (Wu and Chen, 2017). The TCT was recommended as an improved model for the IS continuance that is appropriate for the total life cycle of acceptance (Liao et al., 2009). Three models, technology adoption model (TAM), expectancy confirmation model (ECM) and cognitive model (COGM), with their six constructs, which are confirmations, satisfaction, perceived usefulness, perceived ease of use and attitude, have synthesized to create a condensed model (Dağhan and Akkoyunlu, 2016; Wu and Chen, 2017; Khayer, 2019; Oghuma et al., 2016; Ratten, 2016). The major strong point of the TCT is that satisfaction and attitude are merged into one single continuance model while keeping the well-determined variables of perceived ease of use and usefulness as the first level of antecedent (Liao et al., 2009). Compared with the ECM, TAM and COGM, the TCT was favored for this research because of its explaining power for the adoption of the whole life cycle. According to Liao et al. (2009), unlike the ECM, TAM and COGM models, the TCT qualitatively and quantitatively provide a considerable improvement in order to explain the consumers' attitudes at different stages of confirmation. The TCT quantitatively represents a powerful explanation both for continuance intent and satisfaction. As for the qualitative point of view, the TCT contributes theoretically in that it merges attitude and satisfaction, into one continuance model.

Previous research results have suggested that cognitive needs and subjective norms are significant constructs of attitude and continuance intention to use MLA (Liao et al., 2009) and such constructs could be added to the TCT. The cognitive need is the learners' motivation to use materials as creative thinkers (Hashim et al., 2015; Mondi et al., 2007). Adult learners are supposed to be challenged to integrate their knowledge in their practical work to solve everyday problems while they should develop skills to create new knowledge to solve problems and communicate their knowledge with others (Mondi et al., 2007). For that reason, the current study model has included cognitive needs and subjective norms into the original TCT to predict better the attitude and continuance intention to use the MLA. According to TAM, consumers' attitudes used to determine the users' behavior toward MLA use (Talukder et al., 2019). The literature suggests that attitude has a significant impact on IS use and acceptance (Lee et al., 2011; Liao et al., 2009). As people show a positive perception toward a new system and technology, they are more enthusiastic to take continuance advantage of it. Therefore, it is believed that when users have positive attitudes toward an MLA, they will have a stronger interest to use it (Lee et al., 2011).

\section{Analysing adult learners in using M-learning}


JRIT

14,2

250

A great number of researchers have studied consumer satisfaction which shows the IT effectiveness from the users' points of view (DeLone and McLean, 1992, Dağhan and Akkoyunlu, 2016; Khayer, 2019; Wu and Chen, 2017; Liu et al., 2018; Cao, 2018; Hsiao et al., 2016; Ratten, 2016; Taylor and Hamdy, 2013) and also indicates the success of the IT acceptance in a compulsory environment (Oliver and Westbrook, 1993). The ECM maintains that the continuance intention of users shaped by their satisfaction with using the IS as well as their perceived usefulness of continued IS use. As Oliver (1993) and Lee (2010) believe, adult learners being satisfied with the IS use plays a vital role in forming the IS continuance intent. In the context of the adult learners' satisfaction with the MLA may derive their continuance intention to use.

Users will always want to keep using a particular learning application that can help them improve productivity (Bhattacherjee, 2001; Bhattacherjee and Premkumar, 2004). Moreover, according to Gagne (2007) and Lee (2010), there is a positive relationship between the intention to use and the perceived usefulness of a new product. Moreover, learners need to feel that the MLA is quite easy to use and beneficial. Thus perceived usefulness and perceived ease of use can influence learner attitude and continuance intention (Peng et al., 2016).

Conversely, users might not have the positive usefulness of new technology, mainly because they do not know what to expect from its usage (Hossain et al., 2018). In that case, confirmation experience could be used to adjust the IS perceived usefulness, especially when doubt and uncertainty about what to expect from the IS usage overshadow the consumers' primary perceived usefulness (Bhattacherjee, 2001). However, they are likely to accept the new technology to make their experience of using it as a platform to shape more perceptions. Even though at the initial level of using the IS, there is low perceived usefulness, such perceived usefulness might be modified based on the outcomes of the confirmation experiences. To be more specific, confirmation and disconfirmation, respectively, increases and lessens the degree of the perceived usefulness. (Ghazal et al., 2016).

To visualize these relations, we designed a conceptual model (Figure 1) illustrating seven independent variables and their intersections, as shown on the left, and the outcome of interest, on the right. The overlapped areas represent possible combinations among factors, that is, areas that one factor may exist together with the other factors. Also, to identify such patterns of factors in a complex system as continuous intention to use mobile learning applications, formulating hypotheses, common in variance-based methods that are framed as correlational expressions, does not allow for a holistic approach that will lead

Figure 1.

Venn diagram illustrating the conceptual model that explains intention to use MLA

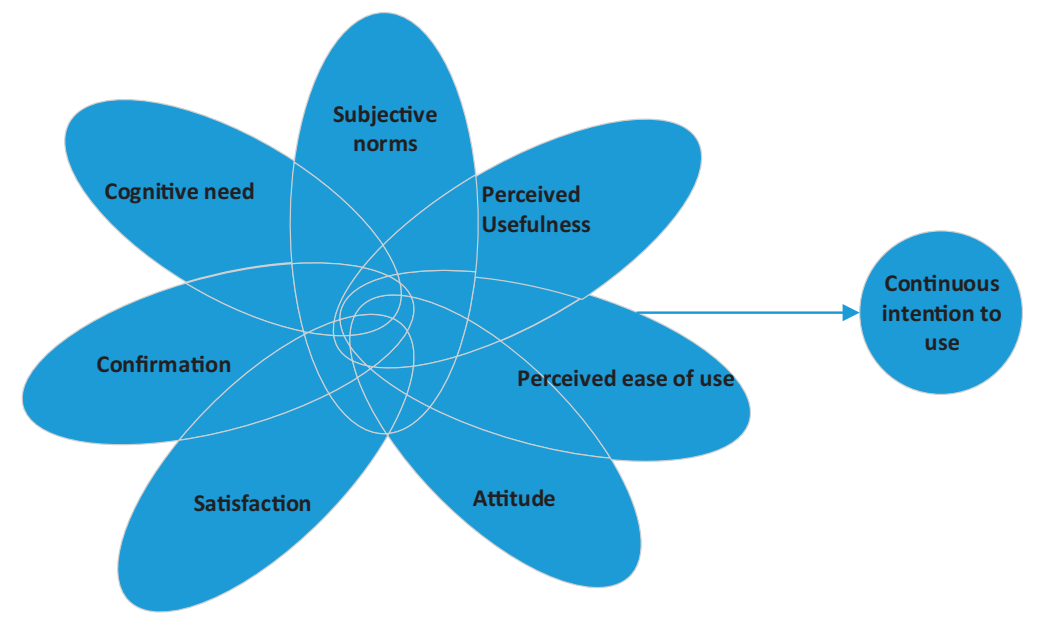


to the identification of multiple solutions. Indeed, Technology Continuous theories need to evolve to capture the complexity of phenomena under investigation (Bagozzi, 2007). Thus, we employ configuration theory approaches in which research propositions are formulated as causal recipes to capture the different combinations among factors, and theoretically specify which should be present or absent from the causal recipe (Sawy et al., 2010; Fiss, 2007; Ragin, 2008).

\section{Research methodology}

Measurement of constructs

Containing 40 items, the questionnaire of this study comprises two parts: the first part asked demographic questions about the participant, and the second part was concerned with items assessing the TCT's theoretical constructs. Demographic information included gender, age, race, occupational status, academic qualification, monthly family income, average monthly transportation cost and length of experience in using the MLA. To ensure content validity, the survey items were derived from those used in previous studies. The scale of the perceived usefulness and perceived ease of use were adapted from Venkatesh and Davis (1996). The confirmation, satisfaction and continuance intention items were adapted from Bhattacherjee and Barfar (2011). The items of the cognitive needs and subjective norms were adapted from Peng et al. (2012). Finally, the attitude was determined using a four-item scale adapted from Taylor and Todd (1995). A 5-point Likert scale was used to measure each item.

\section{Procedures and data collection}

This study was conducted in the central parts of Dhaka in Bangladesh due to the fact that the population of the MLA users was not available and it was impossible to select our sampling element from the population, directly. According to a Hand Phone User Survey conducted, around $57.4 \%$ of mobile users in Bangladesh have a smartphone (Sanou, 2016). This indicates that the majority of people have access to different mobile applications. Thus to facilitate learning for the adult, the Open University of Bangladesh developed MLA (see Table 1). This application helps learners to get interactive communication with teachers and student. A partial registration list of adult learners (age above 30 years) was collected from the Open University of Bangladesh those who registered in the MLA and contact them through email to have an appointment. We applied a nonprobability sampling technique, namely, the accidental sampling in which respondents answered the questionnaire according to their availability and willingness (Gravetter and Forzano, 2018). We selected this technique as it was quicker and easier to manage compared to the other techniques that needed more resources (e.g. technical resources, time). Also, accidental sampling is a common method used in the data collection process in technology adoption research. The survey was conducted in the months from June 2019 to July 2019. A sample of 250 learners was approached and handed a questionnaire. Out of the 240 responses, two were incomplete, 25 respondents mentioned that they are not using MLA though registered in the system. This left a total of 211 valid responses or an $89 \%$ response rate. Freedman (2015) suggested that "if the response rate is high (most interviews are completed), non-response bias is minimal". Therefore, nonresponse bias is not an issue in this paper. After that, we prepared a dataset consisting of 211 records using the SPSS software package. As the dataset contained several corrupt or inaccurate records (e.g. duplicate observations, irrelevant observation, structural errors, incomplete records and missing data), we performed data cleansing method to correct the dataset. We fixed some structural errors (e.g. typos or inconsistent capitalization and mislabeled classes) as well as removed duplicate, irrelevant and missing records.

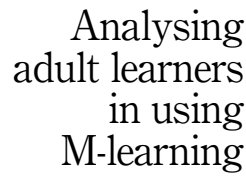




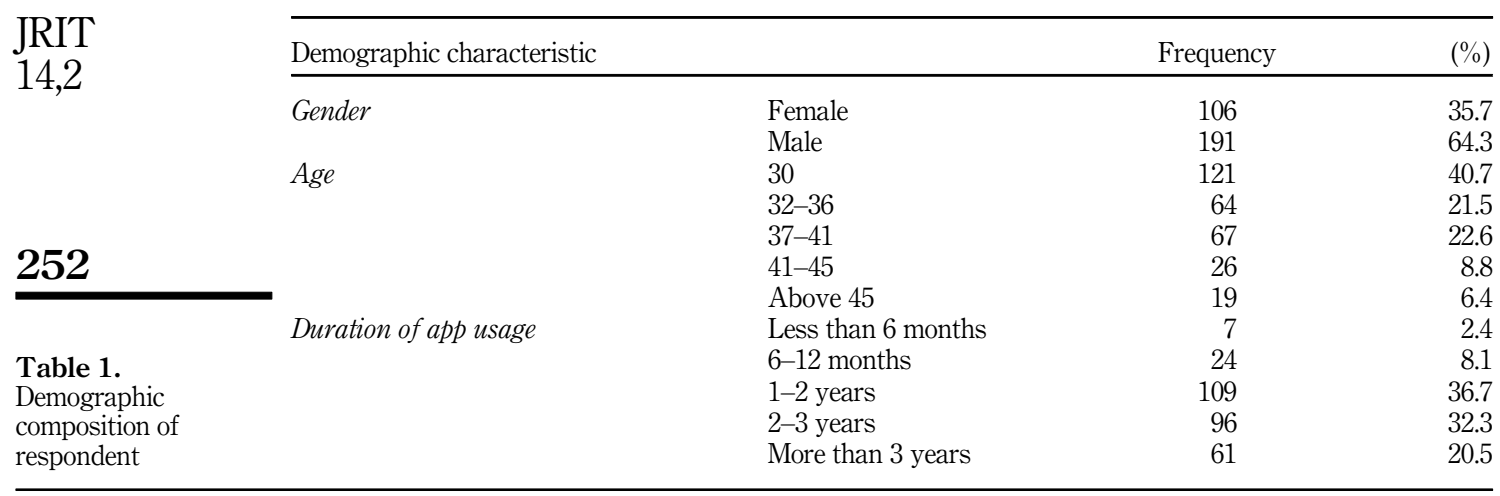

\section{Measurement reliability and validity}

We used internal reliability, convergent validity and discriminant validity criteria to assess the measurement model (Hair et al., 2013). Tables 2 and 3 present the results from our analysis of the measurement model. Convergent validity reflects the degree to which the measures underlying a latent construct assumed to be theoretically connected are in fact, connected (Henseler et al., 2009). Convergent validity can be assessed by estimates of the factor loadings of measurement items as well as the composite reliability $(\mathrm{CR})$ and average variance extracted (AVE) for each construct (Hair et al., 2013).

Results indicate that the factor loadings of all measurement items are above 0.80 . Likewise, the CR scores for all latent constructs are greater than 0.90, and their AVE values are more than 0.7 (Fornell and Larcker, 1981a). Since the values for factor loadings, CR and AVE exceed recommended thresholds of 0.7, 0.8 and 0.5, respectively (see Table 3) (Fornell and Larcker, 1981b), we can be assured of convergent validity in this study (Henseler et al., 2014).

Discriminant validity is assessed by comparing the squared root of the AVE for each latent construct and the cross-loadings for each measurement item (Hair et al., 2016). As shown in Table 2, the squared root of the AVE for each latent construct is higher than its correlations with other constructs (Aldholay et al., 2018). Furthermore, we can deduce that each item is reflective of its underlying latent construct because the within construct loading for an item is higher on its measured construct than its cross-loadings on other constructs (see Table 3). This, in turn, testifies to the discriminant validity of our study (Chin, 1998; Fornell and Larcker, 1981b).

Harman's one-factor test was also performed to determine the existence of common method bias (Podsakoff and Organ, 1986). Results indicate that the largest common variance explained by a single factor was $25.03 \%$, far below the advocated threshold of $50 \%$ of the total variance explained. We can thus eliminate common method bias as a threat to our study (Sharma et al., 2016; Chan and Chong, 2012; Priyadarshinee et al., 2017).

\section{FsQCA}

\section{Data calibration}

Data calibration is necessary when employing fsQCA software. The raw data collected from our survey questionnaire were converted into fuzzy set values before analysis (Ragin, 2000). Following the procedure outlined by Ragin and Fiss (2008), the original scores of the variables in our research model were calibrated to fuzzy membership scores (ranging from 0 to 1 ) by utilizing the calibrating function accessible from the fsQCA 2.5 software. 


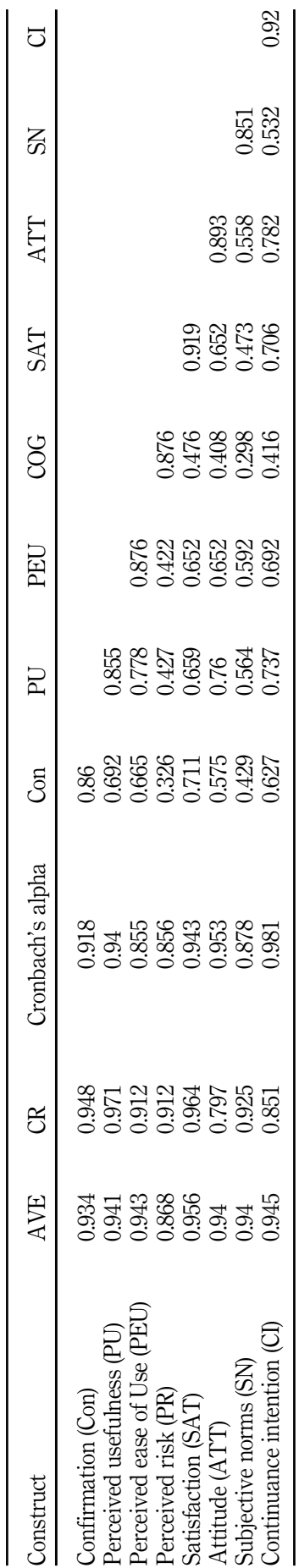

Analysing adult learners in using

M-learning

253

Table 2.

Construct reliability and validity 


\begin{tabular}{|c|c|c|c|c|c|c|c|c|c|}
\hline \multirow{5}{*}{$\begin{array}{l}\text { JRIT } \\
14,2\end{array}$} & & $\mathrm{CN}$ & $\mathrm{PU}$ & PEU & COG & SAT & ATT & SN & $\mathrm{CI}$ \\
\hline & CN1 & 0.86 & & & & & & & \\
\hline & $\mathrm{CN} 2$ & 0.894 & & & & & & & \\
\hline & CN3 & 0.849 & & & & & & & \\
\hline & CN4 & 0.855 & & & & & & & \\
\hline \multirow{21}{*}{254} & PU1 & & 0.84 & & & & & & \\
\hline & PU2 & & 0.869 & & & & & & \\
\hline & $\begin{array}{l}\text { PU3 } \\
\text { PU44 }\end{array}$ & & $\begin{array}{l}0.896 \\
0.942\end{array}$ & & & & & & \\
\hline & $\begin{array}{l}\text { PU4 } \\
\text { PEU1 }\end{array}$ & & & & & & & & \\
\hline & $\begin{array}{l}\text { PEU1 } \\
\text { PEU2 }\end{array}$ & & & 0.814 & & & & & \\
\hline & PEU3 & & & 0.879 & & & & & \\
\hline & PEU4 & & & 0.893 & & & & & \\
\hline & PR1 & & & & 0.854 & & & & \\
\hline & PR2 & & & & 0.897 & & & & \\
\hline & SAT1 & & & & & 0.902 & & & \\
\hline & SAT2 & & & & & 0.932 & & & \\
\hline & SAT3 & & & & & 0.933 & & & \\
\hline & SAT4 & & & & & 0.906 & & & \\
\hline & ATT1 & & & & & & 0.887 & & \\
\hline & ATT2 & & & & & & 0.911 & & \\
\hline & ATT3 & & & & & & 0.889 & & \\
\hline & ATT4 & & & & & & 0.883 & & \\
\hline & SN1 & & & & & & & 0.887 & \\
\hline & SN2 & & & & & & & 0.911 & \\
\hline & SN3 & & & & & & & 0.889 & \\
\hline & SN4 & & & & & & & 0.883 & \\
\hline \multirow{3}{*}{$\begin{array}{l}\text { Table } 3 \text {. } \\
\text { Confirmatory factor } \\
\text { analysis }\end{array}$} & CI1 & & & & & & & & 0.872 \\
\hline & CI2 & & & & & & & & 0.923 \\
\hline & CI3 & & & & & & & & 0.92 \\
\hline
\end{tabular}

Three qualitative breakpoints $(1,0.4$ and 0$)$ were designated to calibrate predictor variables (i.e. perceived usefulness, perceived ease of use, confirmation, satisfaction, attitude, perceived risk and subjective norms) into fuzzy sets. To match the fuzzy set calibration with the 7-point Likert scale employed for data collection, we set the original values of 7, 4 and 1 to correspond, respectively, to the three anchors. A full membership value of 1 was assigned to responses with an answer of 7, 0.4 was assigned to a response of 4 , and 0 was assigned to an answer of 1 . The other values of variables (such as 2, 3, 5 and 6) were calibrated based on the linear function fit into the four values of the variables.

\section{Identifying the configurations}

Following the calibration, the researcher is ready to run the fsQCA algorithm on the menu Analyze and to choose Fuzzy Truth Table Algorithm. At this point, the researcher chooses the outcome of interest (i.e. dependent variable) and all the causal conditions (i.e. independent variables). Regarding the outcome, the researcher may choose to examine the presence of the outcome and choose Set, or the absence of the outcome, Set Negated.

Next, the fsQCA algorithm produces a truth table of $2 \mathrm{k}$ rows, with $\mathrm{k}$ representing the number of outcome predictors and each row representing each possible combination. For example, a truth table between four variables (i.e. conditions) would provide 16 possible logical combinations. For every combination, the minimum membership value is calculated; that is, the degree to which every case supports the specific combination. FsQCA uses the 
threshold of 0.5 to identify the combinations that are acceptably supported by the cases. Thus, all combinations that are not supported by at least one case with membership over the threshold of 0.5 are automatically removed from further analysis.

The final step is to sort the truth table based on frequency and consistency (Ragin, 2008). Frequency describes the number of observations for each possible combination. Consistency refers to "the degree to which cases correspond to the set-theoretic relationships expressed in a solution" (Fiss, 2011). As the truth table computes all possible combinations, some of the combinations will likely have a frequency of zero, meaning that these combinations represent none of the cases in the sample. As the number of variables in the analysis is increased, the combinations increase as well, thus more combinations will have zero frequency. A frequency cut-off point needs to be set to ensure that a minimum number of empirical observations are obtained for the assessment of subset relationships. Increasing the frequency threshold means that each combination will refer to more cases in the sample, but it will reduce the percentage (i.e. coverage) of the sample that is explained by the solutions. On the other hand, a small frequency threshold will increase the coverage of the sample, although each combination will refer to fewer cases in the sample. For small and medium-sized samples, a cut-off point of 1 is appropriate, but for large-scale samples (e.g. 150 or more cases), the cutoff point should be set higher (Ragin, 2008), and can be set at 3. It is up to the researcher to decide if an even larger cut-off point should be set for very large datasets. Thus, after removing the combinations with low frequency using the option on the Edit menu, the truth table should be sorted based on their "raw consistency."

A consistency threshold should be set, with the minimum recommended value being 0.75 (Rihoux and Ragin, 2009). A good indication for choosing this threshold is to identify big changes in the consistency of each combination. For example, one combination may have a consistency of 0.841 and the next one may have 0.781 . Although both values are above the recommended threshold of 0.75 , this is an indication of what the consistency threshold should be. Nonetheless, it is up to the researcher to choose what the exact threshold will be. It should be noted that a low consistency threshold leads to the identification of more necessary conditions, reducing type II errors (i.e. false negatives), but the increasing type I errors (i.e. false positives), and vice versa (Dul, 2016). The final step is to insert the value of 1 or 0 in the column with the outcome variable. Choosing 1 or 0 depends on the consistency threshold that has been chosen. For example, for a consistency threshold of 0.75 , which is set here, all combinations with a consistency larger than 0.75 should be set at 1 and the rest at 0 . Once this is complete, the researcher may proceed with the option of standard analyses.

\section{Obtaining the solutions}

Following the sorting of the truth table, the researcher is presented with the option to choose if a single independent variable should be present or absent at all times on the solutions. Unless otherwise needed, we suggest choosing "Present or Absent" in order to obtain all the possible combinations. Next, fsQCA provides the following three sets of solutions: complex, parsimonious and intermediate. Here, "solution" refers to a combination of conditions that is supported by a high number of cases, where the rule "the combination leads to the outcome" is consistent. The complex solution presents all the possible combinations of conditions when traditional logical operations are applied. In general, because the number of configurations identified can be very large, the number of complex solutions can be large and these may include configurations with several terms. Thus interprets the solution is difficult and in most cases impractical (Mendel and Korjani, 2012). For this reason, they are usually simplified further into parsimonious and intermediate solutions.

The parsimonious solution is a simplified version of the complex solution, based on simplifying assumptions and presents the most important conditions which cannot be left out

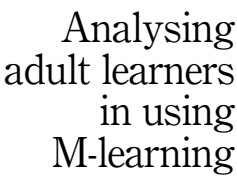

255 
JRIT

14,2

from any solution. These are called "core conditions" (Fiss, 2011) and are identified automatically by fsQCA. Finally, the intermediate solution is obtained when performing a counterfactual analysis of the complex and parsimonious solutions (Ragin, 2008). In essence, the intermediate solution depends on simplifying assumptions that are applied by the researcher, which at all times should be consistent with theoretical and empirical knowledge. The intermediate solution is part of the complex solutions and includes the parsimonious solution. The conditions that are part of the intermediate solution and not part of the parsimonious solution are called "peripheral conditions" (Fiss, 2011). A more detailed and mathematically oriented description of the steps in the counterfactual analysis is provided by Mendel and Korjani (2012).

\section{Interpreting and evaluating the solutions}

FsQCA presents the complex and parsimonious solutions regardless of any simplifying assumptions employed by the researcher, while the intermediate solution depends directly on these assumptions. A combination of the parsimonious and intermediate solutions is recommended as the main point of reference for interpreting the fsQCA results. In detail, the researchers should create a table that will include both core and peripheral conditions (Fiss, 2011; Pappas, Kourouthanassis et al., 2016). This study identifies the conditions of the parsimonious solution and the intermediate solution. This will lead to a combined solution, which will present all core and peripheral conditions, thus helping in the interpretation of the findings. Typically, the presence of a core condition is present with a Capital letter " $\mathrm{C}$ ", the causal condition is presented with "P", the absence with "AB" and the "do not care" condition with a blank space (Fiss, 2011). The researcher should also present the overall solution consistency as well as the overall solution coverage. The overall coverage describes the extent to which the outcome of interest may be explained by the configurations, and may be compared with the $R$-square reported on regression-based methods (Woodside, 2013).

\section{Result}

Results of $f_{S} Q C A$

The study's hypothesis that the presence of perceived usefulness, perceived ease of use, confirmation, satisfaction, attitude, perceived risk and subjective norms should be associated with the presence of our target output of interest; continuance intention toward using MLA, while gender and consistency of use would be related to continuance intention to use regardless of their extant. That is, users' continuance intention should not be dictated by whether they are males or females, or how frequently MLA has been used during a day.

After calibrating the variables, a truth table was constructed to perform qualitative comparative analysis. A truth table encompasses all logically plausible combinations of casual conditions are included. Because there are seven causal conditions (perceived usefulness, social norms, perceived ease of use, confirmation, satisfaction, cognitive needs, subjective norms and attitude) in our research model, the truth table consists of $256\left(2^{\wedge} 8\right)$ distinct combinations or configurations. As the sample cases in a study might be limited and may not necessarily meet all possible configurations in the truth table, the initial truth table must be fine-tuned to isolate relevant configurations by setting a number-of-cases (frequency) threshold (Ragin and Fiss, 2008). After fine-tuning the truth table, the analysis moved to the identification of distinct configurations.

Table 4 depicts the configurations that culminate in a high membership score regarding users' continuance intention toward learning apps. These configurations entail both intermediate and complex solutions. The consistency and coverage (raw coverage and solution coverage) are also reported in Table 4. Consistency measures the extent to which configurations are sufficient for an outcome of interest to emerging (Ragin and Fiss, 2008). 


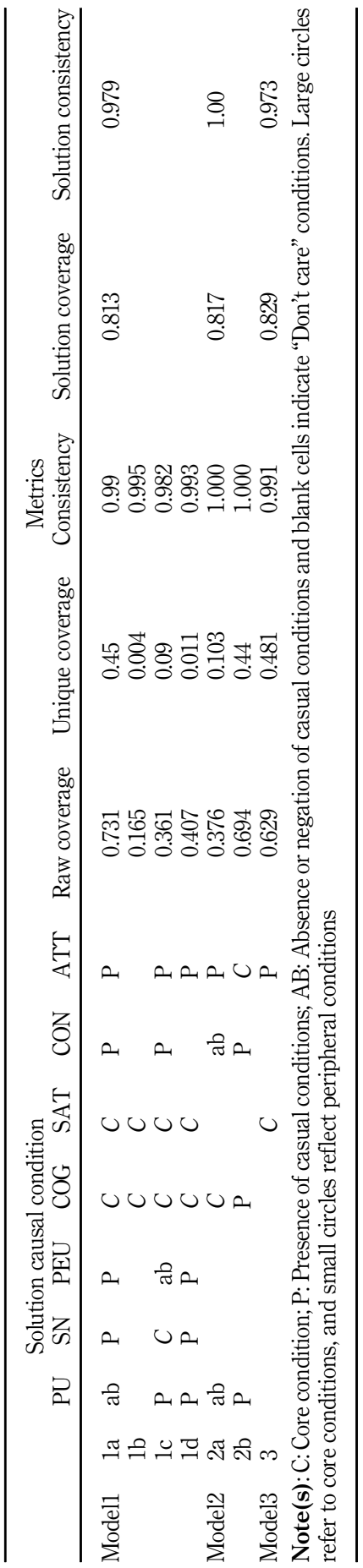

Analysing adult learners in using

M-learning

257

Table 4 Configurations for MLA continuous use 
JRIT

14,2

Solution coverage and raw coverage measure the degree to which the configurations can describe the outcome of interest (Ragin and Fiss, 2008). As articulated by Ragin (2008), the consistency value aids in determining the fit of each configuration. If a configuration exceeds the predefined consistency threshold of 0.75 , the causal conditions it embodies are deemed to be sufficient in generating the outcome.

Conversely, configurations with consistency values below the threshold value of 0.75 are regarded as being insufficient. In this study, we set the consistency threshold at 0.90 to ensure a high membership value for the configurations. As shown in Table 4, the raw coverage values are between 0.165 and 0.960 and the solution coverage value of models 1,2 and 3 is between 0.81 and 0.92. All consistency values exceed the cut-off value of 0.90 . The configurations of continuance intention, as exhibited in the solution table (see Table 4), satisfy the required threshold (Ragin, 2009), thereby indicating all configurations are sufficient in yielding the outcome of interest (Rihoux et al., 2009). Furthermore, as shown in Table 4, the model 1,2 and 3 explains $81.3 \%, 82 \%$ and $92 \%$, respectively, of the cases of continuance intention toward MLA.

Based on the equifinality of different core conditions, both first- and second-order solutions exist in configurations (Fiss, 2011). In this study, we further identified three order equifinality of solutions, within-type equifinality of solution for configuration 1 (i.e. 1a, 1b, 1c and 1d), configuration 2 (2a, 2b) and 3 (3a) (see Table 4).

Results indicate that there are three major configurations of causal conditions that underpin users' continuance intention toward MLA. As shown in Table 4, the pattern of core condition $(\mathbf{C})$, causal condition $(\mathrm{P})$, and do not care conditions vary across the three configurations. As shown in Table 4, Solution 1 includes 4 configurations, covering the membership values of the observations from $16.7 \%$ to $71.0 \%$, whereas Solution 2 covers $37-$ $69.4 \%$ of the membership values, and Solution 3 covers $62.9 \%$ of the membership values. All three solutions represent sufficient configurations of causal conditions for continuance intention and Solution 1 is the most prevalent configuration for predicting users' continuance intention toward MLA.

\section{Discussion and conclusions}

\section{General discussion and theoretical implication}

The present study takes a different approach from traditional technology acceptance research, builds on complexity theory, employs configurational analysis, and proposes that in using MLA, cognitive need, satisfaction, confirmation, subjective norms, perceived usefulness, perceived ease of use and attitude combine to form configurations for predicting MLA adoption. By considering the role of different configurations, this study offers an alternative approach to examining technology adoption and sheds light on how adult learners may have high m-learning application adoption. To this end, a conceptual model is constructed which serves as the basis for identifying the configurations above.

Of particular interest in the findings was the role of cognitive need and satisfaction. Those two factors are present in five out of the seven solutions (Solutions 1a-d and 2a), and when cognitive is absent, high MLA adoption may be achieved only with the satisfaction and strong presence of an attitude (Solutions 3). The results reveal that the cognitive needs and satisfaction of MLA use are joint members of the set of continuance intentions, implying that they constitute core conditions for continued usage of learning apps. Within extant literature, past studies have certified that the learners' cognitive motivation to use materials as creative thinkers (Hashim et al., 2015; Mondi et al., 2008) are supposed to be challenged to integrate their knowledge in their education to solve everyday problems. It is necessary to develop skills continuously to create new knowledge to solve different problems. Therefore, learners will be satisfying to use the service regularly only when it full fill their needs for learning and 
developing skills (Hsiao et al., 2016; Zhang et al., 2006). But at the same time, only satisfaction is not sufficient in driving continuance intention. The cognitive need should be present together with other peripheral factors. In other words, the finding indicates that adult learners should not only use learning apps frequently but they should also feel the ease of the service. Learners will always want to keep using a particular app that can help them improve their efficiency (Bhattacherjee, 2001; Bhattacherjee and Premkumar, 2004). They are always concerned about the certainty of the application. Their confirmation experience plays vital role in post adaption behavior (Bhattacherjee, 2001). For example, users might not have a positive usefulness of a new application, mainly because they do not know exactly what to expect from its usage. Thus, confirmation, usefulness of the service will satisfy the learner need to create positive attitude for continuance use.

Likewise, the first solution embodies four configurations (1a, 1b, 1c, 1d) of casual conditions, showing the major features of the four different subgroups of users. Specifically, Solution 1a indicates that perceived ease of use in combination with cognitive need creates sufficient condition for MLAs' confirmation and satisfaction which leads learners' attitudes to use it continuously. According to users' gratification theory, cognitive needs positively influence on learners' satisfaction. For adult learners', it is the learners' motivation to use MLA and prove them as adopters of new technology to learn differently (Hashim et al., 2015; Mondi et al., 2008). As a result, it highlights cognitive needs in combination with satisfaction, is a sufficient condition in Solution 1b. For informal learners', subjective norms have a significant influence on satisfaction and attitudes. In combination with subjective norms and cognitive needs, it is sufficient in predicting continuance intention and attitude whenever they have confirmation about MLAs' perceived usefulness (Solution 1c).

On the other hand, it is observed that in Solution 1d, perceived ease of use, cognitive needs and perceived usefulness together creating sufficient conditions that influence learners continuance intention if they hold satisfied attitude in this method of learning (Li et al., 2012). This solution is consistent with condition $1 \mathrm{~b}$ (Solution $1 \mathrm{~b}$ ) where learners are not caring much about social norms and confirmation about the service. Because according to selfdetermination theory, learners' motivation plays a vital role in continuance learning intention (Joo et al., 2018).

Similarly, Solution 2a reveals that the cognitive needs of using MLA play an instrumental role in adult learners' continuance intention in spite of the absence of perceived usefulness, perceived ease of use, satisfaction, confirmation and subjective norms. In that case, informal learners are likely to persist even when they have no negative perceptions of usefulness, confirmation, satisfaction, perceived ease of use and social appeal in MLA use (Arbaugh, 2000). In other words, fulfilling cognitive needs could lead to forming a regular activity among adult learners'. Because they will be able to solve their regular problem instantly at their working place by developing new skills and knowledge. In contrast, Solution $2 \mathrm{~b}$ shows that the combination of perceived usefulness and confirmation of the service with the presence of learners' cognitive needs developing sufficient positive conditions. Thus, it will lead learners' attitudes to use service continuously.

As shown in Solution 3a, learners' satisfaction in the absences of other construct is uniquely sufficient for securing their continuance intention behavior toward MLA usage. Because satisfaction is concerned with his or her experience of an IS, which vividly describes the emotional response to the IS (Ives et al., 1983). A good number of researchers have studied consumer satisfaction which shows the IT effectiveness from the users' points of view (DeLone and McLean, 1992) and also indicates the success of the IT depends on its continuance usage in a compulsory environment (Oliver and Westbrook, 1993). Their satisfaction with using the service shapes the continuance intention of users. As Oliver (1993) and Lee (2010) believe, users being satisfied with the IS use plays a vital role in forming the IS

\section{Analysing adult learners in using \\ M-learning}

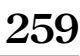


JRIT

14,2 continuance intention. In the context of the MLA, the learners' satisfaction with the learning method may derive their desire to use the application continuance.

Even though some past studies have considered attitude and satisfaction as being synonymous with each other (Bolton and Drew, 1991), most agree that the two are different from a conceptual point of view. While attitude is more stable and goes beyond prior experiences, satisfaction seems to be considered as a momentary experience-related factor (Liao et al., 2013). Attitude is a belief emerging out of the personal evaluation of a system, service and product while satisfaction is an evaluation occurring after purchasing a service or product (Venkatesh and Morris, 2000). So that satisfaction has been analyzed in-depth in the literature and has been found to play a critical role in predicting consumers' continuous behaviors (Iranmanesh et al., 2017; Sayyah Gilani et al., 2017).

Finally, the discussion revealed that cognitive needs and satisfaction indeed play important roles in MLA adoption for adult learners. The finding contradicts with prior studies that adopted technology confirmation theory approach (e.g. Kim and Chatterjee, 2013; Park and Ko, 2012) as well as related work in social influences on learning adoption (e.g. Shin and Kang, 2015; Yeap et al., 2016). They showed that perceived usefulness, social norms and facilitating conditions play a vital role in infrequent use of learning applications. But this study, by employing fsQCA, found that if cognitive need and satisfaction are not present, adult learners definitely need to have a strong presence of m-learning attitude to attain m-learning adoption. On the other hand, if learners have strong cognitive needs and satisfaction toward the service, there is no need form-learning attitude or social influences to have MLA adoption. Thus, this study expands on the research stream on adult learners' continuance use behavior by offering empirical evidence that attests to the applicability of a configurational lens toward MLA.

Regarding the theoretical implications, these findings also contribute to the literature in several ways. This study adds to the technology acceptance literature by providing an alternative view on the adoption process and shows how important antecedents of users' continuance intentions can combine, creating multiple solutions that explain MLA adoption. Following the need to extend and evolve technology continuance theories and models to better capture real-life phenomena, which are by definition complex and multidimensional (Benbasat and Barki, 2007; Nistor et al., 2014), we propose taking a different methodological approach that enables researchers to identify such complexities inherent in real-life situations. The methodology is essential, as it not only defines how we study a phenomenon but also affects how we think about it (Bagozzi, 2007). To this end, we propose employing complexity theory along with configurational analysis, to better explain the complex relationships among variables. Since such relationships are more likely to be asymmetric, researchers with fsQCA can identify different configurations (i.e. combinations) of the same variables predicting the same outcome, explaining, for example, the behavior of different parts of a sample which otherwise would have been considered as outliers and removed from further analysis. Identifying such configurations can help in theory building with fsQCA (Woodside, 2014), as configurations that frequently appear in different contexts provide support for their importance, increasing researchers' knowledge about their role in predicting behavior (Liu et al., 2017). Thus, we differentiate from traditional hypothesis building and assumptions of symmetric tests between individual variables, as the proposed approach can lead to the evolution of existing theories on technology continuance theory and behavior of individuals (e.g. TAM, TRA/TPB). In detail, identifying important configurations of existing variables, in multiple contexts, will offer more knowledge on their interrelations and guide researchers to the creation of new variables, and potentially hypotheses, answering the call for incorporating more complex and multidimensional variables into the field (Benbasat and Barki, 2007; Nistor et al., 2014). 


\section{Practical implications}

In line with the previous studies by Hossain and Quaddus (2013); Bhattacherjee and Barfar (2011), the results reveal the important effects of confirmation and perceived usefulness on satisfaction. Therefore, meeting the expectations of the adult learners ensuring that the MLA is useful. MLA service providers should foster a close relationship with the adult learner to understand their expectations and extend the usefulness of the app to satisfy their users. In the planning and development of learning apps, software developers should pay attention to practical functions and extend key features that are frequently required for solving the problem using a new skill. On the marketing side, MLA companies should emphasize the full functionality of their apps to cater efficiently to the different needs and expectations of the learners.

This research also provides recommendations for MLAs service providers. Gaining a thorough understanding of the determinants of the continuance intention of users toward the learning app use will help the app's service providers to grasp the factors that result in continued learning app use. With such understanding, the service providers can improve their app to ensure its continued use after the first adoption. Since, cognitive need, satisfaction and attitude are critical to the continuance usage of the learning app, the providers of this app should give special notice to those antecedents. The app's service providers can increase the learners' beliefs of how it can enhance their convenience when taking the courses (perceived usefulness) and, consequently, satisfy them by developing an app that fulfills the need for qualification and credential of the learners (confirmation) with a good user interface (perceived ease of use) consistency. The MLA service providers should consider the importance of the perceived usefulness and cognitive need of the MLA in the postadoption stage. The results show that the users' cognitive needs can not only enhance the continuance intention of the MLA use but also influence their satisfaction and attitudes toward using the app.

Finally, the MLA service providers must improve the attitude of the user about using the MLA for learning. Therefore, perceived usefulness and subjective norms should be considered as an important configuration during the app's design and publicity. Furthermore, when the expectations of the MLA service users are met, satisfaction will generate. And only then the cycle of satisfaction and service improvement will run.

\section{Implications for teaching and learning}

This study helps to add important recommendations in the context of teaching and learning. The demand for skill-based employment is increasing tremendously (Taylor and Hamdy, 2013). Thus, it becomes essential for the educator to develop a learning management system based on adult learners' cognitive need (Santandreu Calonge, 2016). If they are satisfied with the teaching and learning materials that help them to upgrade needed skills and knowledge, their continuance intention will increase. Therefore, for the instructor, well-defined content, monitoring and performance assessment procedure should be maintained for the adult learners. Prioritizing interactive features such as threaded discussion, virtual discussion forums and learning community will help them to get actual feedback on their skill and knowledge development. Then adult learners' cognitive needs will be satisfied and continuance intention to use the service will increase. Finally, this study suggests that educator, teacher and professor need to ensure customized administration, documentation, feedback and reporting system to attract and satisfy more adult learners.

\section{Limitations and future research directions}

This paper has a couple of caveats that could be addressed in future research. First, this study was conducted in the context of adult learners MLA whereby the motivations for continued

\section{Analysing adult learners in using \\ M-learning}


JRIT

14,2

262

usage and the nature of technological innovation could differ. In this regard, findings from this study may not be generalizable to other technological contexts. Future research should therefore compare and contrast the antecedents of IS continuance, as derived in this study, against those identified in other contexts. Second, this study was conducted among users. Future research could consider replicating our study across other countries or cultural backgrounds.

This empirical work has some limitations. Adult learners' general perceptions of MLA are examined, without focusing on a specific service. Future studies may choose the specific application of learning systems or content in order to provide more accurate guidelines for professors and designers. In addition, this study examines learners' continuance intentions in m-learning, common in technology acceptance research, but without investigating actual user behavior. Although learners' continuance intention is considered as a powerful predictor of actual behavior (Fishbein and Ajzen, 1977), combining data from the actual use of learning systems and applications would provide more insight into the role of cognitive need, satisfaction, subjective norms and individual factors in predicting m-learning adoption. Future studies should build on learning analytics, and incorporate data from big learning analytics providers (e.g. Moodle), reflecting the use of complex learning ecosystems and offering a holistic understanding of the technology acceptance process in learning.

Nonetheless, in order to increase the reliability of the sample, future studies should ask the respondents to provide an example of what they believe is m-learning. Additionally, more predictors of m-learning adoption should be examined in the future, as well as various demographic characteristics, which have been proven to influence acceptance of m-learning (Wang et al., 2009). Finally, we should mention that fsQCA does not identify the unique contribution of each variable for every solution. Instead, the goal of fsQCA is to identify combinations of the independent variables. Future studies should combine fsQCA with regression-based techniques to gain a deeper insight into the data, and integrate knowledge from both methods toward extending current theories or developing new ones. As this study is among the first to employ configurational analysis with fsQCA in education and learning environments (Pappas, Cetusic et al., 2017; Pappas, Giannakos et al., 2017; Pappas, Giannakos et al., 2016; Plewa et al., 2016), further innovative research is needed to identify complex and important configurations that will move the field forward, and also reveal the full potential of configurational analysis.

\section{Conclusion}

MLAs are popular in adult learners' society because of the flexibility and self-directed nature that can be accessed and used at any place and at any time. Moreover, the popularity of mobile devices is increasing. However, the success of a system's use is dependent on the continuance uses of it, especially for adult learners. Nevertheless, there are limitations to the acceptance of this type of system in developing countries, particularly in Bangladesh because of the lack of proper awareness among adult learners. This form of learning was not a common form of regular adult education in Bangladesh (Shohel and Power, 2010). To promote the continuance use of the MLA, software developer (e.g. Audacity IT solution, Cloud Ten Enterprise, etc.) should collaboratively design a plan with Open Universities of Bangladesh to fill the gaps. Because these universities help adult learners to update their skills and knowledge through courses provided by MLA. Nowadays, skill-based promotion become popular in almost all public and private organizations. Besides dropout learners start to learn a new skill to avail of new skill-based job opportunities. Thus, MLA service provider and software developer companies need to fulfill this cognitive need of students to build positive attitudes that will increase satisfaction toward the new breakthrough learning system. 
Consequently, policymakers in the education sector need to organize regular teachers' training programs to introduce them with a new medium of education. So, the behavior of resistance to change among conventional educators will liberalize.

\section{References}

Ahn, J. and Kahlor, L.A. (2019), "No regrets when it comes to your health: anticipated regret, subjective norms, information insufficiency and intent to seek health information from multiple sources", Health Communication, Vol. 34, pp. 1-8.

Alario Hoyos, C., Pérez Sanagustín, M., Cormier, D. and Delgado Kloos, C. (2014), Proposal for a Conceptual Framework for Educators to Describe and Design MOOCs, J.UCS Publisher, Austria.

Alario-Hoyos, C., Pérez-Sanagustín, M., Delgado-Kloos, C., Muñoz-Organero, M. and Rodríguez-DeLas-Heras, A. (2013), Analysing the Impact of Built-In and External Social Tools in a MOOC on Educational Technologies, European Conference on Technology Enhanced Learning, Springer, Berlin, Heidelberg, pp. 5-18.

Aldholay, A.H., Isaac, O., Abdullah, Z. and Ramayah, T. (2018), "The role of transformational leadership as a mediating variable in DeLone and McLean information system success model: the context of online learning usage in Yemen", Telematics and Informatics, Vol. 35, pp. 1421-1437.

Alias, N., Zakariah, Z., Ismail, N.Z. and Aziz, M.N.A. (2012), "E-learning successful elements for higher learning institution in Malaysia”, Procedia-Social and Behavioral Sciences, Vol. 67, pp. 484-489.

Aliberti, M.J., Cenzer, I.S., Smith, A.K., Lee, S.J., Yaffe, K. and Covinsky, K.E. (2019), "Risk assessment of adverse outcomes for older adults: the need to include both physical and cognitive elements", Journal of the American Geriatrics Society, Vol. 67, p. 477.

Alkin, M.C. (1992), Encyclopedia of Educational Research, Vol. 3, Macmillan.

Arbaugh, J.B. (2000), "Virtual classroom characteristics and student satisfaction with internet-based MBA courses", Journal of Management Education, Vol. 24, pp. 32-54.

Bagozzi, R.P. (2007), "The legacy of the technology acceptance model and a proposal for a paradigm shift", Journal of the Association for Information Systems, Vol. 8 No. 4, p. 3.

Bartolomé-Pina, A.R. and Steffens, K.J.C. (2015), "Son los MOOC una alternativa de aprendizaje? = Are MOOCs Promising Learning Environments?", Comunicar: Revista científica iberoamericana de comunicación y educación, Vol. 22, pp. 91-99.

Benbasat, I. and Barki, H. (2007), Quo vadis TAM?", Journal of the Association for Information Systems, Vol. 8 No. 4, p. 7.

Bhattacherjee, A. (2001), "Understanding information systems continuance: an expectationconfirmation model", MIS Quarterly, Vol. 25, pp. 351-370.

Bhattacherjee, A. and Barfar, A. (2011), "Information technology continuance research: current state and future directions", Journal of Asia Pacific Journal of Information Systems, Vol. 21, pp. 1-18.

Bhattacherjee, A. and Premkumar, G. (2004), "Understanding changes in belief and attitude toward information technology usage: a theoretical model and longitudinal test", MIS Quarterly, Vol. 28, pp. 229-254.

Bhuasiri, W., Xaymoungkhoun, O., Zo, H., Rho, J.J. and Ciganek, A.P. (2012), "Critical success factors for e-learning in developing countries: a comparative analysis between ICT experts and faculty", Computers and Education Vol. 58, pp. 843-855.

Blomqvist, U. (1995), Community Participation in a Refugee Emergency: Focusing on Community Mobilization, Women and Youth: A Report from the Rwandan Camps in the Kagera Region of Tanzania, Rädda Barnen, Tanzenia.

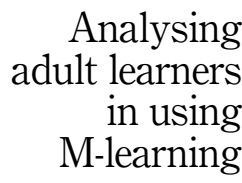

263 
JRIT

14,2

Bolton, R.N. and Drew, J.H. (1991), “A multistage model of customers' assessments of service quality and value", Journal of Consumer Research, Vol. 17, pp. 375-384.

Caffarella, R. and Merriam, S.B. (2000), Linking the Individual Learner to the Context of Adult Learning, pp. 55-70.

Cao, X. (2018), "Understanding mobile payment users' continuance intention: a trust transfer perspective", Internet Research, Vol. 28, pp. 456-476.

Chan, F.T.S. and Chong, A.Y.L. (2012), "A SEM-neural network approach for understanding determinants of interorganizational system standard adoption and performances", Decision Support Systems, Vol. 54, pp. 621-630.

Chang, I.H. and Chen, R.S. (2019), "The impact of perceived usefulness on satisfaction with online parenting resources: the mediating effects of liking and online interaction", Asia-Pacific Edu Res, Vol. 28, doi: 10.1007/s40299-019-00484-y.

Chiang, T.H.C., Yang, S.J. and Hwang, G. (2014), “An augmented reality-based mobile learning system to improve students' learning achievements and motivations in natural science inquiry activities", Journal of Educational Technology and Society, Vol. 17, pp. 352-365.

Chin, W.W. (1998), "The partial least squares approach to structural equation modeling", Modern Methods for Business Research, Vol. 295, pp. 295-336.

Dağhan, G. and Akkoyunlu, B. (2016), "Modeling the continuance usage intention of online learning environments", Computers in Human Behavior, Vol. 60, pp. 198-211.

Delone, W.H. and Mclean, E.R. (1992), "Information systems success: the quest for the dependent variable", Information Systems Research, Vol. 3, pp. 60-95.

Demirkan, H., Goul, M. and Gros, M. (2010), "A reference model for sustainable e-learning service systems: experiences with the joint university/teradata consortium”, Decision Sciences Journal of Innovative Education Vol. 8, pp. 151-189.

Diver, P. and Martinez, I. (2015), "MOOCs as a massive research laboratory: opportunities and challenges", Distance Education, Vol. 36, pp. 5-25.

Dul, J. (2016), "Necessary Condition Analysis (NCA): logic and methodology of "necessary but not sufficient” causality”, Organizational Research Method, Vol. 19 No. 1, pp. 10-52, doi: 10.1177/ 1094428115584005.

Eastmond, D.V. (1998), “Adult learners and internet-based distance education”, New Directions for Adult and Continuing Education, Vol. 78, pp. 33-41.

Farooqui, S. (2007), "Developing speaking skills of adult learners in private universities in Bangladesh: problems and solutions", Australian Journal of Adult Learning, Vol. 47, p. 94.

Fishbein, M. and Ajzen, I. (1977), Belief, Attitude, Intention, and Behavior: An Introduction to Theory and Research.

Fiss, P.C. (2007), “A set-theoretic approach to organizational configurations", Academy of Management Review, Vol. 32 No. 4, pp. 1180-1198.

Fiss, P.C. (2011), "Building better causal theories: a fuzzy set approach to typologies in organization research", Academy of Management Journal, Vol. 54 No. 2, pp. 393-420, doi: 10.5465/amj.2011. 60263120 .

Fornell, C. and Larcker, D.F. (1981a), "Evaluating structural equation models with unobservable variables and measurement error", Journal of Marketing Research, Vol. 18 No. 1, pp. 39-50.

Fornell, C. and Larcker, D.F. (1981b), "Structural equation models with unobservable variables and measurement error: algebra and statistics", Journal of Marketing Research, Vol. 18 No. 1, pp. 382-388.

Freedman, L. (2015), Strategy: A History, Oxford University Press, Oxford.

Gagne, S. (2017), 'Improving adult learners' experience with continuing professional education: a transformational path to andragogy", The Organizational Improvement Plan at Western University, Vol. 23, available at: https://ir.lib.uwo.ca/oip/23. 
Ghazal, M., Akmal, M., Iyanna, S. and Ghoudi, K. (2016), "Smart plugs: perceived usefulness and satisfaction: evidence from United Arab Emirates", Renewable and Sustainable Energy Reviews, Vol. 55, pp. 1248-1259.

Giannakos, M.N., Pappas, I.O., Jaccheri, L. and Sampson, D.G. (2017), "Understanding student retention in computer science education: the role of environment, gains, barriers and usefulness", Education and Information Technologies, Vol. 22 No. 5, pp. 2365-2382, doi: 10.1007/ s10639-016-9538-1.

Giles, M. (2019), "The influence of paired grouping on teacher candidates' attitude towards technology use and integration”, Technology, Pedagogy, Education and Information Technologies, Vol. 28, pp. 363-380.

Govindasamy, T. (2001), "Successful implementation of e-learning: pedagogical considerations", The Internet and Higher Education, Vol. 4, pp. 287-299.

Gravetter, F.J. and Forzano, L.A.B. (2018), Research Methods for the Behavioral Sciences, Cengage Learning, Boston, MA.

Hair, J.R.J.F., Hult, G.T.M., Ringle, C. and Sarstedt, M. (2013), A Primer on Partial Least Squares Structural Equation Modeling (PLS-SEM), Sage Publications, New Jersey, NJ.

Hair, J.R., Hult, G.T.M., Ringle, C. and Sarstedt, M. (2016), A Primer on Partial Least Squares Structural Equation Modeling (PLS-SEM), Sage Publications, Thousand Oaks, CA.

Hashim, K.F., Tan, F.B. and Rashid, A. (2015), “Adult learners' intention to adopt mobile learning: a motivational perspective", British Journal of Educational Technology, Vol. 46, pp. 381-390.

Henseler, J., Ringle, C.M. and Sinkovics, R.R. (2009), "The use of partial least squares path modeling in international marketing", Advances in International Marketing, Vol. 20, pp. 277-319.

Henseler, J., Ringle, C.M. and Sarstedt, M. (2014), "A new criterion for assessing discriminant validity in variance-based structural equation modeling", Journal of the Academy of Marketing Science, Vol. 43, pp. 115-135.

Ho, C.H. (2010), "Continuance intention of e-learning platform: toward an integrated model", International Journal of Electronic Business Management, Vol. 8, p. 206.

Holsapple, C.W. and Lee-Post, A.J. (2006), "Defining, assessing, and promoting e-learning success", An Information Systems Perspective, Vol. 4, pp. 67-85.

Hossain, M.A. and Quaddus, M. (2013), "Does mandatory pressure increase RFID adoption? A case study of Western Australian livestock industry", International Working Conference on Transfer and Diffusion of IT, Springer, Berlin, Heidelberg, pp. 184-202.

Hossain, M.N., Talukder, M.S., Hoque, M.R. and Bao, Y. (2018), "The use of open government data to citizen empowerment: an empirical validation of a proposed model", Foresight, Vol. 20, pp. 665-680.

Hsiao, C.H., Chang, J.J. and Tang, K.Y. (2016), "Exploring the influential factors in continuance usage of mobile social Apps: satisfaction, habit, and customer value perspectives", Telematics and Informatics, Vol. 33, pp. 342-355.

Hsu, C.L. and Lin, J.C.C. (2019), "Understanding continuance intention to use online to offline (O2O) apps”, Electronic Markets, Vol. 29, doi:10.1007/s12525-019-00354-x.

Huang, H.-M. (2002), "Toward constructivism for adult learners in online learning environments", British Journal of Educational Technology, Vol. 33 No. 1, pp. 27-37, doi:10.1111/1467-8535.00236.

Huang, Y.M. (2019), "Examining students' continued use of desktop services: perspectives from expectation-confirmation and social influence", Computers in Human Behavior, Vol. 96, pp. 23-31.

Ifinedo, P. (2006), "Acceptance and continuance intention of web-based learning technologies (wlt) use among university students in a Baltic country", The Electronic Journal of Information Systems in Developing Countries, Vol. 23, pp. 1-20.
Analysing
adult learners
in using
M-learning

265 
Iranmanesh, M., Zailani, S. and Nikbin, D. (2017), "RFID continuance usage intention in health care industry", Quality Management in Health Care, Vol. 26, pp. 116-123.

Ives, B., Olson, M.H. and Baroudi, J. (1983), "The measurement of user information satisfaction", Communications of the ACM, Vol. 26, pp. 785-793.

Jamila, M. (2014), "Lack of confidence-A psychological factor Affecting spoken English of university level adult learners in Bangladesh", Language in India, Vol. 14 No. 10, p. 14.

Jarvis, P. (1990), An International Dictionary of Adult and Continuing Education, 1st ed., Routledge.

Joo, Y.J., So, H.J. and Kim, N.H. (2018), "Examination of relationships among students' selfdetermination, technology acceptance, satisfaction, and continuance intention to use KMOOCs", Computers and Education, Vol. 122, pp. 260-272.

Jordan, K. (2015), "Massive open online course completion rates revisited: assessment, length and attrition", International Review of Research in Open and Distributed Learning, Vol. 16, pp. 341-358.

Katz, R.N. (1999), Dancing with the Devil: Information Technology and the New Competition in Higher Education, Jossey-Bass Publishers, San Francisco, CA.

Khayer, A. (2019), "The continuance usage intention of Alipay: integrating context-awareness and technology continuance theory (TCT)”, The Bottom Line, Vol. 32, pp. 211-229.

Kibelloh, M. and Bao, Y. (2014), "Perceptions of international female students toward e-learning in resolving high education and family role strain”, Journal of Educational Computing Research, Vol. 50, pp. 467-487.

Kim, J. and Chatterjee, S. (2013), "Childhood financial socialization and young adults' financial management", Journal of Financial Counseling \& Planning, Vol. 24 No. 1.

Knowles, H. (1998), A Theory of Adult Learning: Andragogy.

Lee, M.C. (2010), "Explaining and predicting users' continuance intention toward e-learning: an extension of the expectation-confirmation model", Computers and Education, Vol. 54, pp. 506-516.

Lee, Y.H., Hsieh, Y.C. and Hsu, C.N. (2011), "Adding innovation diffusion theory to the technology acceptance model: supporting employees' intentions to use e-learning systems”, Journal of Educational Technology and Society, Vol. 14, pp. 124-137.

Leung, L. and Chen, C. (2019), "E-health/m-health adoption and lifestyle improvements: exploring the roles of technology readiness, the expectation-confirmation model, and health-related information activities", Telecommunications Policy, Vol. 43, pp. 563-575.

Li, Y., Duan, Y., Fu, Z. and Alford, P. (2012), "An empirical study on behavioural intention to reuse elearning systems in rural China", British Journal of Educational Technology, Vol. 43, pp. 933-948.

Liao, C., Palvia, P. and Chen, J.L. (2009), "Information technology adoption behavior life cycle: toward a technology continuance theory (TCT)", International Journal of Information Management, Vol. 29, pp. 309-320.

Liao, Y., Liu, T., Cheng, Y., Wang, J., Deng, Y., Hao, W., Chen, X., Xu, Y., Wang, X. and Tang, J. (2013), "Changes in eating attitudes, eating disorders and body weight in Chinese medical university students”, International Journal of Social Psychiatry, Vol. 59, pp. 578-585.

Lieblein, E. (2000), "Critical factors for successful delivery of online programs", The Internet and Higher Education Vol. 3, pp. 161-174.

Lin, K.M., Chen, N.S. and Fang, K. (2011), "Understanding E-learning continuance intention: a negative critical incidents perspective", Behaviour and Information Technology, Vol. 30, pp. 77-89.

Liu, Y., Mezei, J., Kostakos, V. and Li, H. (2017), “Applying configurational analysis to IS behavioural research: a methodological alternative for modelling combinatorial complexities", Information Systems Journal, Vol. 27, pp. 59-89. 
Liu, C., Lu, J. and Yu, C.-S. (2018), Examining Wechat Social Commerce Continuance Intention and Use Incorporating Personality Traits, Association for Computing Machinery, Hangzhou, China.

Loetscher, T., Potter, K.J., Wong, D. and Das Nair, R. (2019), "Cognitive rehabilitation for attention deficits following stroke", Cochrane Database of Systematic Reviews, No. 11, doi: 10.1002/ 14651858.CD002842.pub3.

Loh, C.S., Sheng, Y. and Ifenthaler, D. (2015), "Serious games analytics: theoretical framework", in Loh, C., Sheng, Y. and Ifenthaler, D. (Eds), Serious Games Analytics. Advances in Game-Based Learning, Springer, Cham, pp. 3-29.

Mendel, J.M. and Korjani, M.M. (2012), “Charles Ragin's fuzzy set qualitative comparative analysis (fsQCA) used for linguistic summarizations”, Information Sciences, Vol. 202, pp. 1-23, doi: 10. 1016/j.ins.2012.02.039.

Mondi, M., Woods, P. and Rafi, A. (2007), "Students' 'uses and gratification expectancy'conceptual framework in relation to e-learning resources", Asia Pacific Education Review, Vol. 8, pp. 435-449.

Mondi, M., Woods, P. and Rafi, A. (2008), "A 'uses and gratification expectancy model'to predict students perceived e-learning experience", Journal of Educational Technology and Society, Vol. 11, pp. 241-261.

Morris, T.A. (2010), "Anytime/anywhere online learning: does it remove barriers for adult learners?", in Online Education and Adult Learning: New Frontiers for Teaching Practices, IGI Global, pp. 115-123.

Nistor, N., Lerche, T., Weinberger, A., Ceobanu, C. and Heymann, O. (2014), "Towards the integration of culture into the Unified Theory of Acceptance and Use of Technology", British Journal of Educational Technology, Vol. 45 No. 1, pp. 36-55, doi:10.1111/j.1467-8535.2012.01383.x.

Oghuma, A.P., Libaque-Saenz, C.F., Wong, S.F. and Chang, Y. (2016), "An expectation-confirmation model of continuance intention to use mobile instant messaging", Telematics and Informatics, Vol. 33, pp. 34-47.

Oliver (1993), "Cognitive, affective, and attribute bases of the satisfaction response", Journal of Consumer Research, Vol. 20, pp. 418-430.

Oliver, R. and Westbrook, R. (1993), "Profiles of consumer emotions and satisfaction in ownership and usage", Emotion, Vol. 6, pp. 12-27.

Pappas, I.O., Giannakos, M.N. and Jaccheri, L. (2016), "Investigating Factors Influencing Students' Intention to Dropout Computer Science Studies", Paper presented at the Proceedings of the 2016 ACM Conference on Innovation and Technology in Computer Science Education, Arequipa, doi: 10.1145/2899415.2899455.

Pappas, I.O., Cetusic, L., Giannakos, M.N. and Jaccheri, L. (2017), "Mobile learning adoption through the lens of complexity theory and fsQCA", in 2017 IEEE Global Engineering Education Conference (EDUCON), IEEE, pp. 536-541.

Pappas, I.O., Kourouthanassis, P.E., Giannakos, M.N. and Lekakos, G. (2017), "The interplay of online shopping motivations and experiential factors on personalized e-commerce: a complexity theory approach", Telematics and Informatics, Vol. 34 No. 5, pp. 730-742.

Park, N. and Ko, Y. (2012), Computer Education's Teaching-Learning Methods Using Educational Programming Language Based on STEAM Education, Berlin, Heidelberg.

Park, Y. and El Sawy, O.A. (2012), "Discovering the multifaceted roles of information technologies with a holistic configurational theory approach", System Science (HICSS), 2012 45th Hawaii International Conference on, IEEE, pp. 5204-5212.

Pender, N.J. and Pender, A.R. (1986), "Attitudes, subjective norms, and intentions to engage in health behaviors", Nursing Research, Vol. 35, pp. 15-18. 
JRIT

14,2

Peng, W., Lin, J.-H., Pfeiffer, K.A. and Winn, B. (2012), "Need satisfaction supportive game features as motivational determinants: an experimental study of a self-determination theory guided exergame”, Media Psychology, Vol. 15, pp. 175-196.

Peng, X.B., Berseth, G. and Van De Panne, M. (2016), "Terrain-adaptive locomotion skills using deep reinforcement learning", ACM Transactions on Graphics, Vol. 35, p. 81.

Plewa, C., Ho, J., Conduit, J. and Karpen, I.O. (2016), "Reputation in higher education: a fuzzy set analysis of resource configurations", Journal of Business Research, Vol. 69 No. 8, pp. 3087-3095, doi: 10.1016/j.jbusres.2016.01.024.

Podsakoff, P.M. and Organ, D.W. (1986), "Self-reports in organizational research: problems and prospects", Journal of Management Education, Vol. 12, pp. 531-544.

Priyadarshinee, P., Raut, R.D., Jha, M.K. and Gardas, B.B. (2017), "Understanding and predicting the determinants of cloud computing adoption: a two staged hybrid SEM - neural networks approach", Computers in Human Behavior, Vol. 76, pp. 341-362.

Ragin, C. (2000), Fuzzy-set Social Science, University of Chicago Press, Chicago.

Ragin, C.C. (2008), "Measurement versus calibration: a set theoretic approach", in The Oxford Handbook of Political Methodology, Oxford Handbook Online, doi: 10.1093/oxfordhb/ 9780199286546.003.0008.

Ragin, C.C. (2009), Redesigning Social Inquiry: Fuzzy Sets and Beyond, University of Chicago Press, Chicago.

Ragin, C.C. and Fiss, P.C. (2008), Redesigning Social Inquiry: Fuzzy Sets, United States of America, University of Chicago Press, Chicago.

Rakoczy, K., Pinger, P., Hochweber, J., Klieme, E., Schütze, B. and Besser, M. (2019), "Formative assessment in mathematics: mediated by feedback's perceived usefulness and students' selfefficacy", Learning and Instruction, Vol. 60, pp. 154-165.

Ratten, V. (2016), "Continuance use intention of cloud computing: innovativeness and creativity perspectives", Journal of Business Research, Vol. 69, pp. 1737-1740.

Rihoux, B., Ragin, C., Yamasaki, S. and Bol, D. (2009), Conclusions-The Way (S) Ahead.

Roberts, A.R., De Schutter, B., Franks, K. and Radina, M.E. (2019), "Older adults' experiences with audiovisual virtual reality: perceived usefulness and other factors influencing technology acceptance", Clinical Gerontologist, Vol. 42, pp. 27-33.

Ruey, S. (2010), "A case study of constructivist instructional strategies for adult online learning", British Journal of Educational Technology, Vol. 41 No. 5, pp. 706-720, doi: 10.1111/j.1467-8535. 2009.00965.x.

San Martín, H., Herrero, A. and García De Los Salmones, M.D.M. (2019), "An integrative model of destination brand equity and tourist satisfaction", Current Issues in Tourism, Vol. 22, pp. 1992-2013.

Sanou, B. (2016), "ICT facts and figures 2016", International Telecommunication Union (ITU) Fact Sheet, pp. 4-6.

Santandreu Calonge, D. and Aman Shah, M. (2016), "MOOCs, graduate skills gaps, and employability: a qualitative systematic review of the literature", International Review of Research in Open and Distributed Learning: IRRODL, Vol. 17 No. 5, pp. 67-90.

Sawy, O.A.E., Malhotra, A., Park, Y. and Pavlou, P.A. (2010), "Research commentary-seeking the configurations of digital ecodynamics: it takes three to tango", Information Systems Research, Vol. 21 No. 4, pp. 835-848, doi: 10.1287/isre.1100.0326.

Sayyah Gilani, M., Iranmanesh, M., Nikbin, D. and Zailani, S. (2017), "EMR continuance usage intention of healthcare professionals", Informatics for Health and Social Care, Vol. 42, pp. 153-165.

Sela, E. and Sivan, Y. (2009), "Enterprise e-learning success factors: an analysis of practitioners' perspective (with a downturn addendum)", Interdisciplinary Journal of E-Learning and Learning Objects, Vol. 5, pp. 335-343. 
Selim, H.M. (2007), "Critical success factors for e-learning acceptance: Confirmatory factor models", Computers and Education, Vol. 49, pp. 396-413.

Sharma, S.K., Al-Badi, A.H., Govindaluri, S.M. and A-Kharusi, M.H. (2016), "Predicting motivators of cloud computing adoption: a developing country perspective", Computers in Human Behavior, Vol. 62, pp. 61-69.

Shin, W.S. and Kang, M. (2015), "The use of a mobile learning management system at an online University and its effect on learning satisfaction and achievement", International Review of Research in OpenDistributed Learning, Vol. 16 No. 3, pp. 110-130, doi: 10.19173/irrodl.v16i3.1984.

Shohel, M.M.C. and Power, T. (2010), "Distance and e-learning introducing mobile technology for enhancing teaching and learning in Bangladesh: teacher perspectives", Open Learning: The Journal of Open, Distance and e-Learning, Vol. 25, pp. 201-215.

Song, J., Almeida, P. and Wu, G. (2003). "Learning-by-Hiring: when is mobility more likely to facilitate interfirm knowledge transfer?”, Management Science, Vol. 49, pp. 351-365.

Swan, K., Shea, P., Fredericksen, E.E., Pickett, A.M. and Pelz, W.E. (2000), "Course Design Factors Influencing the Success of Online Learning. In Proceedings of WebNet World Conference on the WWW and Internet 2000", Association for the Advancement of Computing in Education (AACE), San Antonio, TX, pp. 513-518.

Talukder, M.S., Chiong, R., Bao, Y. and Hayat Malik, B. (2019), "Acceptance and use predictors of fitness wearable technology and intention to recommend: an empirical study", Industrial Management and Data Systems, Vol. 119, pp. 170-188.

Tarkiainen, A. (2005), "Subjective norms, attitudes and intentions of Finnish consumers in buying organic food”, British Food Journal, Vol. 107, pp. 808-822.

Taylor, D.C.M. and Hamdy, H. (2013), "Adult learning theories: implications for learning and teaching in medical education: AMEE Guide No. 83”, Medical Teacher, Vol. 35, pp. e1561-e1572.

Taylor, S. and Todd, P.A. (1995), "Understanding information technology usage: a test of competing models", Information Systems Research, Vol. 6, pp. 144-176.

Thongsri, N., Shen, L. and Bao, Y. (2019), "Investigating academic major differences in perception of computer self-efficacy and intention toward e-learning adoption in China", Innovations in Education and Teaching International, Vol. 56, pp. 1-13.

Tight, M. (2000), "Critical perspectives on management learning: a view from adult/continuing/ lifelong education", Management Learning, Vol. 31 No. 1, pp. 103-119, doi: 10.1177/ 1350507600311008.

Tuijnman, A. (1996), International Encyclopedia of Adult Education and Training, Pergamon Press.

Venkatesh, V. and Davis, F.D. (1996), "A model of the antecedents of perceived ease of use: development and test", Journal of Decision Sciences, Vol. 27, pp. 451-481.

Venkatesh, V. and Morris, M.G. (2000), "Why don't men ever stop to ask for directions? Gender, social influence, and their role in technology acceptance and usage behavior", MIS Quarterly, Vol. 24 No. 1, pp. 115-139.

Venkatesh, V., Morris, M.G., Davis, G.B. and Davis, F.D. (2003), "User acceptance of Information Technology: toward a unified view", Mis Quarterly, Vol. 27 No. 3, pp. 425-478, doi: 10.2307/ 30036540.

Volery, T. and Lord, D. (2000), "Critical Success Factors in Online Education”, International Journal of Educational Management, Vol. 14, pp. 216-223.

Wang, Y.-S., Wu, M.-C. and Wang, H.-Y. (2009), "Investigating the determinants and age and gender differences in the acceptance of mobile learning", British Journal of Educational Technology, Vol. 40 No. 1, pp. 92-118.

Wang, Y.N., Jin, L. and Mao, H. (2019), "Farmer cooperatives' intention to adopt agricultural information technology - mediating effects of attitude”, Information Systems Frontiers, Vol. 21, pp. 565-580.

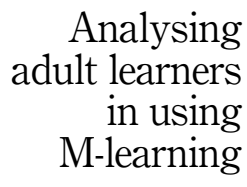

269 
JRIT

14,2
Weng, C., Tsai, C.C. and Weng, A. (2015), "Social support as a neglected e-learning motivator affecting trainee's decisions of continuous intentions of usage", Australasian Journal of Educational Technology, Vol. 31.

Willroth, E.C., John, O.P., Biesanz, J.C. and Mauss, I.B. (2019), "Understanding short-term variability in life satisfaction: the individual differences in evaluating life satisfaction (IDELS) model", Journal of Personality and Social Psychology, Vol. 119.

Woodside, A.G. (2013), Moving beyond Multiple Regression Analysis to Algorithms: Calling for Adoption of a Paradigm Shift from Symmetric to Asymmetric Thinking in Data Analysis and Crafting Theory, Elsevier, The Netherlands.

Woodside, A.G. (2014), "Embrace perform model: complexity theory, contrarian case analysis, and multiple realities", Journal of Business Research, Vol. 67 No. 12, pp. 2495-2503.

$\mathrm{Wu}, \mathrm{B}$. and Chen, X. (2017), "Continuance intention to use MOOCs: integrating the technology acceptance model (TAM) and task technology fit (TTF) model", Computers in Human Behavior, Vol. 67, pp. 221-232.

Yeap, J.A., Ramayah, T. and Soto-Acosta, P. (2016), "Factors propelling the adoption of m-learning among students in higher education", Electronic Markets, Vol. 26 No. 4, pp. 323-338.

Zhang, D., Zhou, L., Briggs, R.O. and Nunamaker, J. Jr (2006), "Instructional video in e-learning: assessing the impact of interactive video on learning effectiveness", Information and Management, Vol. 43, pp. 15-27.

\section{Corresponding author}

Yukun Bao can be contacted at: yukunbao@hust.edu.cn

For instructions on how to order reprints of this article, please visit our website: 